http://dx.doi.org/10.1590/1678-4162-8791

Arq. Bras. Med. Vet. Zootec., v.68, n.6, p.1621-1628, 2016

\title{
Monitoramento e conservação genética de populações naturais de Prochilodus lineatus dos rios Pardo, Mogi-Guaçu e Tietê, São Paulo
}

[Monitoring and conservation genetics of Prochilodus lineatus wild populations of Pardo, Mogi Guaçu and Tiete rivers, São Paulo]

\author{
N.M. Lopera-Barrero ${ }^{1}$, S.C.A. Santos ${ }^{2}$, E.S.R. Goes ${ }^{3}$, P.L. Castro ${ }^{3}$, F.P. Souza ${ }^{1}$, A.R. Poveda-Parra ${ }^{1}$, \\ J. Casseta ${ }^{3}$, B.G. Pontillo ${ }^{3}$, R.P. Ribeiro ${ }^{3}$ \\ ${ }^{1}$ Universidade Estadual de Londrina - Londrina, PR \\ ${ }^{2}$ Autônomo - Promissão, SP \\ ${ }^{3}$ Universidade Estadual de Maringá - Maringá, PR
}

\section{RESUMO}

O objetivo do presente estudo foi determinar a diversidade e a estrutura genética de seis populações naturais de Prochilodus lineatus em usinas hidrelétricas (UHE) dos rios Pardo (UHE Limoeiro - LMO), Mogi-Guaçu (UHE Mogi-Guaçu - MOG) e Tietê (UHE Promissão - PRO, UHE Barra Bonita - BAB, UHE Nova Avanhandava - NAV e UHE Bariri - BAR). Foi encontrado um total de 47 alelos, com tamanhos entre $118 \mathrm{pb}$ e $330 \mathrm{pb}$. Os resultados de heterozigosidade média observada $(0,490$ a 0,625$)$ refletiram uma alta variabilidade genética intrapopulacional. Os valores de distância genética $(0,149$ a 0,773), Fst $(0,006$ a 0,218) e Nm $(1,2$ a 4,2) mostraram a presença de similaridade genética entre as populações. De acordo com a AMOVA, houve maior variação dentro das populações do que entre elas. O dendograma mostrou a formação de dois agrupamentos (LMO-PRO-MOG e BAR-BAB-NAV). Concluiu-se que as populações naturais apresentaram alta variabilidade genética, com similaridade genética entre elas, possivelmente causada pelo programa de repovoamento realizado nesses rios.

Palavras-chave: curimba, marcadores microssatélites, peixe, preservação, variabilidade genética

\section{ABSTRACT}

The aim of this study was to determine the genetic diversity and structure of six wild populations of Prochilodus lineatus in Hydroelectric Power Plants (HPP) of the Pardo (HPP Limoeiro - LMO), Mogi Guacu (HPP Mogi-Guaçu - MOG), and Tiete (HPP Promissão - PRO, HPP Barra Bonita - BAB, HPP Nova Avanhandava - NAV and HPP Bariri - BAR) rivers. A total of 47 alleles, ranging in size from 118bp to 330bp were found. The results of observed heterozygosity average (0.490 to 0.625$)$ reflected a high intra-population genetic variability. The values of genetic distance (0.149 to 0.773), Fst (0.006 to 0.218), and Nm (1.2 to 4.2) showed that between the populations there is genetic similarity. According to AMOVA there was higher variation within populations than between them. The dendrogram demonstrated the formation of two groups (LMO-PRO-MOG and BAR-BAB-NAV). It was concluded that wild populations had high genetic variability with genetic similarity between them, possibly caused by the restocking program performed in these rivers.

Keywords: curimba, microsatellite markers, fish, preservation, genetic variability

\section{INTRODUÇÃO}

O curimba, Prochilodus lineatus (Valenciennes, 1836), conhecido também como curimbatá, grumatã ou papa-terra (Characiformes: Prochilodontidae) é uma espécie migratória endêmica das bacias formadas pelos rios Paraná e Paraguai. Atualmente essa espécie apresenta uma diminuição do número de populações naturais principalmente devido à contaminação dos rios, à sobrepesca e à construção de usinas

Recebido em 2 de outubro de 2015

Aceito em 20 de abril de 2016

E-mail: nelson.peixegen@gmail.com hidrelétricas (Ribolli et al., 2012; Lopera-Barrero et al., 2013; Pinsk e Palumbi, 2014).

A redução do tamanho populacional de espécies nativas pode ser mitigada por estratégias de monitoramento de populações naturais, bem como pelo restabelecimento de fluxo gênico entre as populações (Marteleto, 2015). Nesse contexto, os programas de repovoamento de peixes nativos estão sendo cada vez mais utilizados como estratégias de conservação (Ribeiro et al., 2015). 
A implantação de um programa de repovoamento eficiente deve sempre buscar a preservação da variabilidade genética das populações de peixes nativos. Por isso, a primeira providência a ser tomada na implantação desses programas é verificar a variabilidade genética dos reprodutores e das populações naturais, tendo em vista que estoques com baixa variabilidade genética ou a diminuição desta ao longo das gerações podem gerar futuramente problemas de endogamia (Lopera-Barrero et al., 2010). Esta, por sua vez, promove a perda da adaptabilidade e diminui a sobrevivência das progênies, sendo fundamental a manutenção da diversidade genética em estoques naturais (Povh et al., 2008).

As ferramentas mais utilizadas na determinação e na conservação da diversidade e da estrutura genética de populações naturais de peixes são os marcadores moleculares, sendo os microssatélites um dos mais usados na atualidade (Abdul-Muneer, 2014). Alguns estudos recentes envolvendo conservação de espécies nativas migradoras têm mostrado resultados efetivos por meio da utilização de marcadores moleculares microssatélites (Lopera-Barrero et al., 2014; Ribeiro et al., 2015).

Dessa forma, o objetivo do presente estudo foi determinar a diversidade e a estrutura genética de seis populações naturais de $P$. lineatus dos rios Pardo, Mogi-Mirim e Tietê, por meio de marcadores microssatélites.

\section{MATERIAL E MÉTODOS}

Este estudo foi realizado de acordo com as normas internacionais de bem-estar animal, após aprovação pelo Comitê de Ética em Experimentação Animal (protocolo n 203/2012).

Foram coletadas 48 amostras de nadadeira $\left(1 \mathrm{~cm}^{2}\right.$ aproximadamente) de seis populações naturais de reservatórios localizados nos rios Pardo, MogiGuaçu e Tietê, no estado de São Paulo. As amostras foram conservadas em álcool $70 \%$, até a realização das análises genéticas (Tab. 1).

Tabela 1. Abreviatura, número de amostras, início de operação e especificação dos locais de coleta das populações de Prochilodus lineatus analisadas

\begin{tabular}{|c|c|c|c|c|c|c|}
\hline Populações & Abreviatura & $\begin{array}{l}\text { Número } \\
\text { de } \\
\text { amostras }\end{array}$ & Rio & $\begin{array}{l}\text { Início de } \\
\text { operação }\end{array}$ & Latitude & Longitude \\
\hline UHE Limoeiro & LMO & 4 & Pardo & 1958 & $21^{\circ} 37^{\prime} 30^{\prime \prime} \mathrm{S}$ & $47^{\circ} 00^{\prime} 34^{\prime \prime} \mathrm{W}$ \\
\hline UHE Mogi- Guaçu & MOG & 4 & Mogi-guaçu & 1999 & $22^{\circ} 22^{\prime} 46^{\prime \prime} \mathrm{S}$ & $46^{\circ} 54^{\prime} 01^{\prime \prime} \mathrm{W}$ \\
\hline UHE Promissão & PRO & 7 & Tietê & 1975 & $21^{\circ} 17^{\prime} 52^{\prime \prime} \mathrm{S}$ & $49^{\circ} 47^{\prime} 20^{\prime \prime} \mathrm{W}$ \\
\hline UHE Barra Bonita & $\mathrm{BAB}$ & 23 & Tietê & 1963 & $22^{\circ} 31^{\prime} 10^{\prime \prime} \mathrm{S}$ & $48^{\circ} 32^{\prime} 00^{\prime \prime} \mathrm{W}$ \\
\hline UHE Nova & NAV & 4 & Tietê & 1982 & $21^{\circ} 07^{\prime} 05^{\prime \prime} \mathrm{S}$ & $50^{\circ} 12^{\prime} 02^{\prime \prime} \mathrm{W}$ \\
\hline \multicolumn{7}{|l|}{ Avanhandava } \\
\hline UHE Bariri & BAR & 6 & Tietê & 1965 & $22^{\circ} 09^{\prime} 11^{\prime \prime} \mathrm{S}$ & $48^{\circ} 45^{\prime} 08^{\prime \prime} \mathrm{W}$ \\
\hline
\end{tabular}

Para extração de DNA, foi utilizado o protocolo de extração com $\mathrm{NaCl}$ (Lopera-Barrero et al., 2008). Para avaliar a concentração total de DNA, as amostras foram mensuradas por meio do espectrofotômetro PICODROP ${ }^{\circledR} \quad$ (Picodrop Limited, Hinxton, Reino Unido) utilizando-se uma concentração de $10 \mathrm{ng} / \mu \mathrm{L}$. A integridade do DNA foi avaliada em gel de agarose $1 \%$ corado com SYBR Safe ${ }^{\mathrm{TM}}$ DNA Gel Stain (Invitrogen, Carlsbad CA, EUA), sendo a eletroforese conduzida em tampão TBE 0,5 X $(250 \mathrm{mM}$ Tris$\mathrm{HC1}, 30 \mathrm{mM}$ ácido bórico e 41,5mM EDTA) por uma hora a $70 \mathrm{~V}$. O gel foi visualizado em aparelho transiluminador com luz ultravioleta, sendo a imagem fotografada utilizando-se o programa Kodak EDAS (1D Image Analysis 3.5 Kodak, EUA).
O DNA foi amplificado para um volume final de reação de $15 \mu \mathrm{L}$. Utilizou-se $1 \mathrm{X}$ do tampão Tris$\mathrm{KCl}, 2,0 \mathrm{mM}$ de $\mathrm{MgCl}_{2}, 0,8 \mu \mathrm{M}$ de cada primer (Forward e Reverse), 0,2mM de cada dNTP, uma unidade de Platinum Taq DNA Polimerase e 20ng de DNA de cada amostra. Inicialmente o DNA foi desnaturado a $94^{\circ} \mathrm{C}$ por quatro minutos e, em seguida, foram realizados 30 ciclos, cada um consistindo de 30 segundos de desnaturação a $94^{\circ} \mathrm{C} ; 30$ segundos de anelamento (sendo a temperatura variável para cada primer) e um minuto de extensão a $72^{\circ} \mathrm{C}$. Depois se realizou uma extensão final a $72^{\circ} \mathrm{C}$ por 10 minutos. Foram amplificados 10 primers: P101, Pli30, Pli43 e Pli60 (Yazbeck e Kalapothaki, 2007) e Par12, Par14, Par21, Par43, Par80 e Par82 (Barbosa et al., 2006; Barbosa et al., 2008) (Tab. 2). As reações foram conduzidas em 
termociclador Veriti ${ }^{\circledR}$ (Applied Biosystems ${ }^{\circledR}$, Austin, TX, EUA).

As amostras amplificadas foram submetidas à eletroforese em gel de poliacrilamida $10 \%$ (acrilamida:bisacrilamida - 29:1) desnaturante (6M de ureia) e conduzidas em tampão TBE $1 \mathrm{X}$ (90mM de Tris-Borato e $2 \mathrm{mM}$ de EDTA) com $180 \mathrm{~V}$ e $250 \mathrm{~mA}$ por oito horas.
Para a visualização dos alelos, foi utilizada a coloração com nitrato de prata (Bassam et al., 1991) modificado. O gel foi submetido a uma solução de fixação (10\% de etanol e $0,5 \%$ de ácido acético) por 20 minutos, corado com $6 \mathrm{mM}$ de nitrato de prata por 10 minutos e posteriormente visualizado $(0,75 \mathrm{M}$ de $\mathrm{NaOH}$ e $0,22 \%$ de formol-40\%) e fotografado com câmera Nikon CoolPix 5200.

Tabela 2. Número de acesso, repetição, sequência e temperatura de anelamento dos primers utilizados na análise das populações de Prochilodus lineatus

\begin{tabular}{|c|c|c|c|}
\hline $\begin{array}{l}\text { Primers }\left(\mathrm{n}^{\circ} \mathrm{de}\right. \\
\text { acesso do } \\
\text { GENBANK) }\end{array}$ & Repetição & Sequência $5^{\prime}-3^{\prime}$ & $\begin{array}{c}\text { Temperatura de } \\
\text { anelamento } \\
\left({ }^{\circ} \mathrm{C}\right)\end{array}$ \\
\hline \multirow[t]{2}{*}{ P101 (AY176774) } & $(\mathrm{AATTT})_{10}$ & F: TGACTGTGAACACGGTCACGC & 56 \\
\hline & & R: ACACAGTAGAACATACCTCTG & \\
\hline \multirow[t]{2}{*}{$\operatorname{Pli30}\left(\operatorname{sem} n^{\circ}\right)$} & (GTCT)n $116 \mathrm{pb}$ & F:GATGTCGGTTCTTGTACAGTGGTG & 66 \\
\hline & & R:AGCTGCTGAGGATTCTGGGTCAC & \\
\hline \multirow[t]{2}{*}{$\operatorname{Pli} 43\left(\operatorname{sem~n}^{\circ}\right)$} & $(\mathrm{GT})_{13}$ & F: AGTCCACTCCTTAGGCGAGTGAG & 60 \\
\hline & & R: ATAGACGGGCATGTGTCACAGCT & \\
\hline \multirow[t]{2}{*}{$\operatorname{Pli60}\left(\operatorname{sem~n}^{\circ}\right)$} & $(\mathrm{GA})_{13}$ & F: GCTAGGACGGTTAGCGTCCACTG & 69 \\
\hline & & R: CGACACGTACATCATTACCTCGG & \\
\hline \multirow[t]{2}{*}{ Par 12 (DQ367228) } & $(\mathrm{AAAC})_{7}$ & F: CGAGCTGGTACCGTCACATA & 54 \\
\hline & & R: AGCATGATGCAAAGGATCTG & \\
\hline \multirow[t]{2}{*}{ Par14 (DQ367230) } & $(\mathrm{TGTC})_{5}$ & F: GTATTAGGGGAGAGAATTTG & 48 \\
\hline & & R: TCTCATCAGTTATCACCAAC & \\
\hline \multirow{2}{*}{ Par21 (DQ367233) } & $(\mathrm{ATGA})_{6}$ & F:CAAAAGGATAAGTAGCTCAG & 47 \\
\hline & & R: AGCTCTGTTTATGATGACC & \\
\hline \multirow[t]{2}{*}{ Par43 (DQ367237) } & $(\mathrm{GA})_{6}(\mathrm{CA})_{2}(\mathrm{CAGA})_{4}(\mathrm{GA})_{21}$ & F: GCGTCTGACTCGTTACCTC & 50 \\
\hline & & R: ACCTCATTCCCTCAAGTGC & \\
\hline \multirow[t]{2}{*}{ Par80 (DQ524176) } & $(\mathrm{CT})_{37}$ & F: CTAACCTACAAACCTCATTC & 52 \\
\hline & & R: CTGTAAAAGCTCCACTTATC & \\
\hline \multirow[t]{2}{*}{ Par82 (DQ524177) } & $(\mathrm{CT})_{27}$ & F:CTCTAACAAGGTGAAACAAC & 52 \\
\hline & & R: TTTAAACTGTAGGCACAGAC & \\
\hline
\end{tabular}

O tamanho dos alelos foi calculado utilizando-se DNA ladder (Invitrogen) de 10, 50 e 100pb. O número de alelos, a heterozigosidade observada (Ho) e esperada (He), o teste do equilíbrio de Hardy-Weinberg (HWE) e o número de migrantes $(\mathrm{Nm})$ foram calculados pelo programa GENEPOP 4.0.6 (Rousset, 2008). No teste HWE, a deficiência ou o excesso de heterozigotos para os primers foi baseado no teste exato de Fisher e calculado pelo método da cadeia de Markov (Markov chain length: 100,000; dememorizations: 10,000). A frequência alélica e a distância genética (DG) foram calculadas utilizando-se o programa PopGene 1.31 (Yeh et al., 1999). A riqueza alélica $(\mathrm{Ra})$ foi calculada usando-se FSTAT 2.9.3.2 (Goudet, 2005). A presença de alelos nulos foi verificada por meio do programa Micro-Checker 2.2.3 (Van Oosterhout et al.,
2004). O índice de diferenciação genética - Fst, o desequilíbrio de ligação e a análise de variância molecular - AMOVA foram estimados pelo programa Arlequim 3.1 (Excoffier et al., 2005). Nestas duas últimas análises, as populações foram analisadas formando todas as combinações possíveis (15 no total). Como método de diferenciação dos valores de Fst, foi utilizada a definição de Wright (1978), em que valores entre 0,00 e 0,$05 ; 0,051$ e 0,$15 ; 0,151$ e 0,25 e $>0,25$ indicam pequena, moderada, alta e elevada diferenciação genética, respectivamente. Utilizando-se a análise UPGMA, foi construído um dendrograma baseado na distância genética de Nei (1978), por meio do programa MEGA, versão 5.0 (Tamura et al., 2011). 


\section{RESULTADOS}

No total, 47 alelos foram detectados para os indivíduos das seis populações naturais. Os primers utilizados foram polimórficos e amplificaram alelos microssatélites consistentes e reproduzíveis, com tamanhos entre 118pb (PL01) e 330pb (Pli30). Os primers que apresentaram maior número de alelos foram o Par12 e o Par82 (seis alelos), seguidos do Pli43, Pli60 e Par80 (cinco alelos). A média do número de alelos por primer, por população, caracterizou-se entre 3,1 (LMO) e 4,6 (BAB) (Tab. $3)$.

Tabela 3. Número de amostras $(\mathrm{N})$, número de alelos por primer $(\mathrm{Na})$, heterozigose observada (Ho), heterozigose esperada $(\mathrm{He})$, riqueza alélica $(\mathrm{Ra})$ e teste do equilíbrio de Hardy-Weinberg (HW) para as populações naturais de Prochilodus lineatus

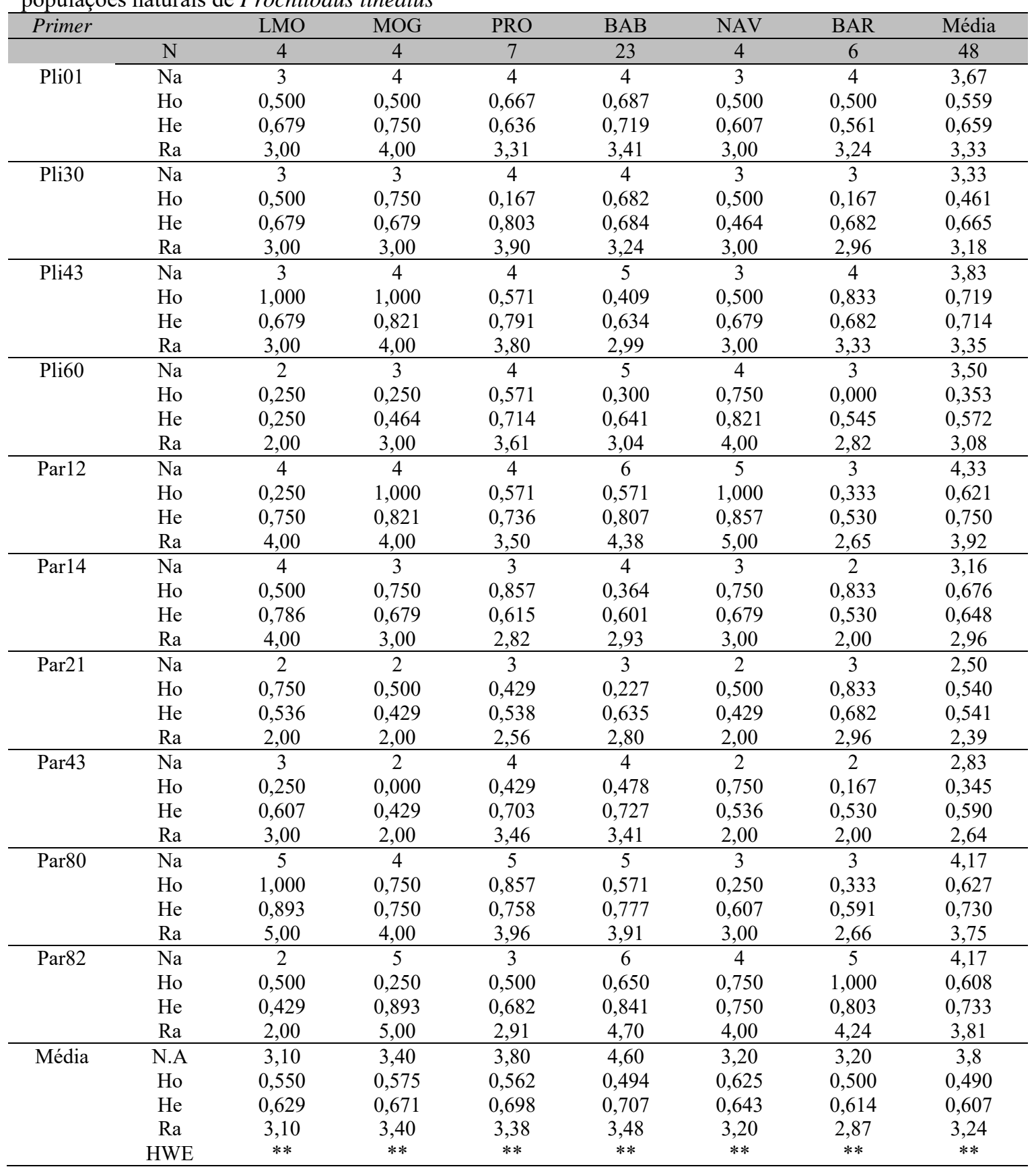

**Significativo $(\mathrm{P}<0,01)$. 
Houve diferença $(\mathrm{P}<0,01)$ entre a heterozigosidade observada (Ho) e a esperada (He) em todas as populações naturais para todos os primers. A Ho média em cada primer apresentou valores entre 0,345 (Par43) e 0,719 (Pli43). De acordo com pesquisas realizadas em populações naturais de Prochilodus (Hatanaka et al., 2006; Carvalho-Costa et al., 2008), a Ho média foi alta $(>45 \%)$ para todas as populações estudadas, caracterizando uma alta variabilidade genética intrapopulacional. Em termos comparativos, os maiores valores de Ho verificados foram observados em NAV $(0,625)$ e MOG $(0,575)$, e os menores em $\operatorname{BAR}(0,500)$ e $\mathrm{BAB}(0,494)$. A riqueza alélica $(\mathrm{Ra})$ foi diferente entre as populações $(\mathrm{P}<0,05)$, apresentando valores entre 2,87 (BAR) e 3,48 (BAB). A riqueza apresentou maior valor no Par12 $(3,92)$ e menor valor no primer Par21 $(2,39)$.
Os dados de distância genética mostraram diferenças entre as populações. Os valores variaram entre 0,149 (BAB x NAV) e 0,773 (MOG $x$ BAR). Os valores do índice de diferenciação genética (Fst) corroboraram esses resultados, denotando pequena, moderada e alta diferenciação das populações de acordo com a classificação de Wright (1978). Da mesma forma, o resultado do número de migrantes $(\mathrm{Nm})$ mostrou a presença de fluxo gênico entre as populações, com valores entre 1,2 e 4,2 indivíduos por geração (Tab. 4). Os resultados da AMOVA mostraram que essa variação genética $(\mathrm{P}<0,05)$ é maior dentro dos grupos do que entre os grupos (Tab. 5). Finalmente, o dendrograma obtido por meio do UPGMA mostrou a formação de dois agrupamentos: LMO-PRO-MOG e BARBAB-NAV (Fig. 1).

Tabela 4. Índice de fixação (Fst), classificação de Wright (Wr), distância genética (DG), e número de migrantes $(\mathrm{Nm})$ para as combinações das populações naturais de Prochilodus lineatus

\begin{tabular}{ccccccccc}
\hline Populações & LMOxMOG & LMOxPRO & LMOxBAB & LMOxNAV & LMOxBAR & MOGxPRO & MOGxBAB & MOGxNAV \\
\hline Fst & 0,041 & 0,006 & 0,028 & 0,121 & 0,176 & 0,056 & 0,062 & 0,149 \\
Wr & Pequena & Pequena & Pequena & Moderada & Alta & Moderada & Moderada & Moderada \\
DG & 0,199 & 0,181 & 0,290 & 0,385 & 0,515 & 0,189 & 0,273 & 0,527 \\
Nm & 2,6 & 3,2 & 2,6 & 1,7 & 1,4 & 3,3 & 3,0 & 1,5 \\
\hline Populações & MOGxBAR & PROxBAB & PROxNAV & PROxBAR & BABxNAV & BABxBAR & NAVxAR \\
\hline Fst & 0,218 & 0,078 & 0,076 & 0,181 & 0,046 & 0,050 & 0,101 & Moderada \\
Wr & Alta & Moderada & Moderada & Alta & Pequena & Pequena & 0,297 \\
Dg & 0,773 & 0,244 & 0,398 & 0,624 & 0,149 & 0,198 & 2,1 \\
Nm & 1,2 & 4,0 & 2,0 & 1,5 & 4,2 & 3,7 & \\
\hline
\end{tabular}

Tabela 5. Porcentagem de variação entre e dentro das combinações das populações de Prochilodus lineatus obtida por meio da análise de variância molecular (AMOVA)

\begin{tabular}{cccccccccc}
\hline Populações & LMOxMOG & LMOxPRO & LMOxBAB & LMOxNAV & LMOxBAR & MOGxPRO & MOGxBAB & MOGxNAV \\
\hline Entre & 4,15 & 0,59 & 2,77 & 12,13 & 17,60 & 5,66 & 6,21 & 14,86 \\
Dentro & 95,85 & 99,41 & 97,23 & 87,87 & 82,40 & 94,34 & 93,79 & 85,14 \\
\hline Populações & MOGxBAR & PROxBAB & PROxNAV & PROxBAR & BABxNAV & BABxBAR & NAVxBAR & Todas \\
\hline Entre & 21,82 & 7,78 & 7,64 & 18,12 & 4,60 & 5,12 & 10,11 & 6,53 \\
Dentro & 78,18 & 92,22 & 92,36 & 81,88 & 95,40 & 94,88 & 89,89 & 93,47 \\
\hline
\end{tabular}

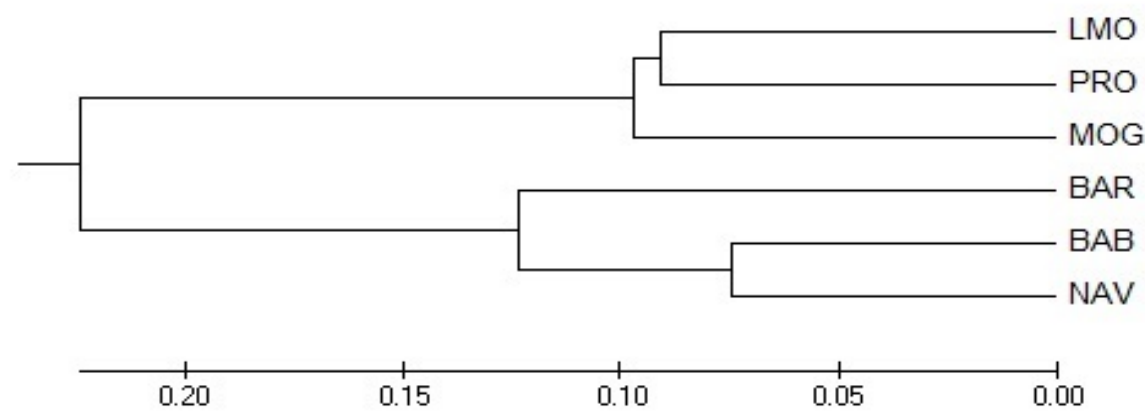

Figura 1. Dendrograma baseado nos complementos aritméticos dos coeficientes de similaridade de Nei (1978), para as populações naturais de Prochilodus lineatus. 


\section{DISCUSSÃO}

O número de alelos obtidos por meio dos primers P101 foi similar ao observado em outro estudo (Hatanaka et al., 2006). Por outro lado, o número de alelos obtidos com Pli30, Pli43, Pli60, Par12, Par14, Par21, Par43, Par80 e Par82 foi menor que o observado em outras pesquisas (Barbosa et al., 2006; Yazbeck e Kalapothakis, 2007; Barbosa et al., 2008; Marteleto, 2015). Essa diferença no número de alelos observados em comparação com outros estudos pode ter sido causada pelas metodologias utilizadas para as análises alélicas (eletroforese em gel de poliacrilamida ou genotipagem por meio de sequenciador) (Marteleto, 2015), ou pela distinta localização geográfica das populações naturais amostradas, que apresentam diferentes conjuntos alélicos, específicos para cada local.

A diferença $(\mathrm{P}<0,01)$ entre Ho e He em todas as populações naturais caracterizou-se pelo déficit de heterozigotos sob o equilíbrio de HardyWeinberg (HWE), diferença que sugere uma divisão populacional. Contudo, os resultados de Ho média foram altos para todas as populações. Isto caracterizou uma adequada variabilidade genética intrapopulacional, indicando que, apesar do déficit de heterozigotos observado, a variabilidade foi mantida. $O$ déficit de heterozigotos em um ou mais primers e a perda de alelos podem indicar a presença de alelos nulos, o efeito Wahlund, ou a combinação de ambos (Hatanaka et al., 2006; GonzálezWanguemert et al., 2012). A análise realizada por meio do programa Micro-Checker 2.2.3 apontou a possível presença de 11 alelos nulos; isso demonstra a influência desses fatores no déficit de heterozigotos observado. Outros estudos utilizando marcadores microssatélites na análise de populações de Prochilodus também encontraram resultados similares (Hatanaka et al., 2006; Carvalho-Costa et al., 2008).

Deve-se destacar que as amostragens realizadas nas UHE mais antigas (entrada em operação entre 1958 e 1965) foram as que apresentaram uma menor variabilidade genética. Esses resultados podem ser atribuídos a uma diminuição do número de indivíduos presentes nas populações naturais, causada possivelmente pelos impactos das barragens (fragmentação do habitat), sobrepesca, contaminação e degradação ambiental, ou a participação paralela de todos eles. Entretanto, não é possível determinar se um ou todos esses fatores estão afetando a variabilidade genética nos locais amostrados.

Tratando-se de rios impactados por barragens e hidrelétricas, a primeira hipótese a ser proposta seria encontrar uma fragmentação do habitat e, consequentemente, dos ciclos reprodutivos de espécies de peixes migratórios, fato que teria como principal efeito a formação de estruturação populacional. Nesse contexto, Barroca et al. (2012), ao avaliarem populações de Prochilodus costatus de três locais a montante e a jusante da Barragem Gafanhoto, no Rio Paraná, encontraram níveis elevados de diversidade genética dentro das populações e diferenciação significativa entre elas, indicando que a barragem promoveu fragmentação do habitat e limitação do fluxo gênico entre as populações. No presente trabalho, apesar da alta diferenciação genética de Wright observada em algumas combinações (LMO x BAR, MOG x BAR e PRO x BAR) e da formação de dois agrupamentos no dendrograma de distância genética de Nei, de forma geral os valores de distância genética (baixas distâncias genéticas), AMOVA (maior diferenciação dentro dos grupos), Fst (pequena e moderada diferenciação genética) e $\mathrm{Nm}$ (alto número de migrantes) evidenciaram similaridade genética entre as populações amostradas. Dessa forma, a barreira geográfica (diferentes rios) e a barreira física artificial (barragens) não influenciaram a presença de mecanismos de fragmentação e estruturação dessas populações.

Cinco das seis barragens estudadas no presente estudo (LMO, PRO, BAB, NAV e BAR) possuem início de operação maior que 30 anos. Devido ao longo tempo de instalação e à barreira física imposta nesses rios, esperava-se encontrar estruturação genética entre as UHE. Iwersen (2010), ao analisar populações de Prochiodus lineatus coletadas em diferentes pontos da bacia do Rio Uruguai, observou a formação de estruturação populacional, fato que, segundo o autor, não pode ser atribuído às barragens construídas no local devido ao pequeno tempo de implantação (UHE Itá: 1987 e UHE Machadinho: 2002). Dessa forma, pressupõe-se que a similaridade genética observada entre as populações pode ser justificada pelo efeito do programa de repovoamento realizado há mais de 20 anos nos rios estudados, onde a soltura de 
alevinos de $P$. lineatus pode ter contribuído para a homogeneização das populações avaliadas. Em relação às populações naturais amostradas no rio Tietê, Lopera-Barrero et al. (2015) observaram igualmente similaridade genética entre elas, fato que, além de ser atribuído à influência do programa de repovoamento, também pode estar relacionado com o efeito da hidrovia TietêParaná. Contudo, maiores estudos devem ser realizados para a maior compreensão da variabilidade genética populacional dessa espécie, de preferência em conjunto com as centrais de repovoamento, a fim de estipular a real influência desses programas sobre as populações naturais.

O monitoramento genético utilizando marcadores moleculares é fundamental para compreender a variabilidade e a estrutura genética de populações naturais, principalmente quando se trata de peixes migradores como o $P$. lineatus. Assim, é importante ressaltar que empreendimentos e projetos na área de conservação promovidos por UHE em conjunto com instituições de ensino superior são de grande importância para programas de repovoamento de espécies nativas.

\section{CONCLUSÃO}

Foi observada alta variabilidade genética nas seis populações naturais avaliadas, com pequena, moderada e alta diferenciação genética entre elas ocasionada possivelmente pelo programa de repovoamento realizado nos rios.

\section{AGRADECIMENTOS}

Os autores agradecem à AES Tietê, pelo apoio logístico e econômico, e aos estudantes, funcionários, técnicos e pesquisadores dos Núcleos de Pesquisa PeixeGen e Nepag.

\section{REFERÊNCIAS}

ABDUL-MUNEER, P.M. Application of microsatellite markers in conservation genetics and fisheries management: recent advances in population structure analysis and conservation strategies. Genet. Res. Int., v.2014, p.1-11, 2014.
BARBOSA, A.C.D.R.; CORRÊA, T.C.; GALZERANI, F. et al. Thirteen polymorphic microsatellite loci in the Neotropical fish Prochilodus argenteus (Characiformes, Prochilodontidae). Mol. Ecol. Notes, v.6, p.936938, 2006.

BARBOSA, A.C.D.R.; GALZERANI, F.; CORRÊA, T.C. et al. Description of novel microsatellite loci in the Neotropical fish Prochilodus argenteus and cross-amplification in P. costatus and P. lineatus. Genet. Mol. Biol., v.31, p.357-360, 2008.

BARROCA, T.M.; SANTOS, G.B.; DUARTE, N.V.R.; KALAPOTHAKIS, E. Evaluation of genetic diversity and population structure in a commercially important freshwater fish Prochilodus costatus (Characiformes, Prochilodontidae) using complex hypervariable repeats. Genet. Mol. Res., v.11, p.4456-4467, 2012

BASSAM, B.J; CAETANO-ANOLLÉS, G.; GRESSHOFF, P.M. Fast and sensitive silver staining of DNA in polyacrylamide gels. Anal. Biochem., v.196, p.80-83, 1991.

CARVALHO-COSTA, L.F.; HATANAKA, T.; GALETTI JR, P.M. Evidence of lack of population substructuring in the Brazilian freshwater fish Prochilodus costatus. Genet. Mol. Biol., v.31, p.377-380, 2008.

EXCOFFIER, L.; LAVAL, G; SCHNEIDER, S. Arlequin ver. 3.0: an integrated software package for population genetics data analysis. Evol. Bioinform Online, v.1, p.47-50, 2005.

GONZÁLEZ-WANGUEMERT, M.; FERNÁNDEZ, T.V.; PÉREZ-RUZAFA, A. et al. Genetic considerations on the introduction of farmed fish in marine protected areas: the case of study of white seabream restocking in the Gulf of Castellammare (Southern Tyrrhenian sea). J. Sea Res., v.68, p.41-48, 2012.

GOUDET. J. FSTAT: A Program to estimate and test gene diversities and fixation indices (version 2.9.3.2). Switzerland: UNIL - Department of Ecology and Evolution, 2005. Available in: $<$ http//www.unil.ch/izea/softwares/fstat.html $>$ Accessed in: 22 Sept. 2015. 
HATANAKA, T.; HENRIQUE-SILVA, F.; GALETTI JR, P.M. Population substructuring in a migratory freshwater fish Prochilodus argenteus (Characiformes, Prochilodontidae) from the São Francisco river. Genetica, v.126, p.153-159, 2006.

IWERSEN, L.H.L. Diversidade genética em curimba Prochilodus lineatus (pisces, characiformes) na bacia do alto Rio Uruguai, Brasil. 2010. 76f. Dissertação (Mestrado em Aquicultura) - Faculdade de Ciências Agrárias, Universidade Federal de Santa Catarina, Florianópolis, SC.

LOPERA-BARRERO, N.M.; ALVAREZ, C.A.R.; RODRIGUEZ-RODRIGUEZ, M.P. et al. Diversidade genética e paternidade de progênies de Brycon orbignyanus obtidas por diferentes sistemas reprodutivos. Semin. Cienc. Agrar., v.35, p.541-554, 2014.

LOPERA-BARRERO, N.M.; POVH, J.A.; RIBEIRO, R.P. et al. Comparación de protocolos de extracción de ADN con muestras de aleta y larva de peces: extracción modificada con sal $(\mathrm{NaCl})$. Cienc. Investig. Agrar., v.35, p.77-86, 2008.

LOPERA-BARRERO, N.M.; SANTOS, S.C.A.; RODRIGUEZ-RODRIGUEZ, M.P. et al. Genetic diversity of wild populations and broodstocks of curimba for restocking programs in the Tietê, Grande, Pardo and Mogi Guaçu rivers (Brazil). Bol. Inst. Pesca, v.41, p.287-304, 2015.

LOPERA-BARRERO, N.M.; VARGAS, L.; SIROL, R.N. et al. Caracterização genética de Brycon orbignyanus utilizando o sistema seminatural. Arq. Bras. Med. Vet. Zootec., v.62, p.184-191, 2010.

LOPERA-BARRERO, N.M; POVH, J.A.; FORNARI, D.C. et al. Genetic diversity of Prochilodus lineatus stocks using in the stocking program of Tietê river, Brazil. Rev. MVZ Córdoba, v.18, p.3759-3766, 2013.

MARTELETO, F.M. Os efeitos da introdução de barreiras artificiais em rios sobre a genética populacional em peixes. 2015. 102f. Tese (Doutorado em Ecologia e Conservação) Faculdade de Ciências Biológicas, Universidade Federal do Paraná, Curitiba, PR.
NEI, M. Estimation of average heterozygosity and genetic distance from a small number of individuals. Genetics, v.89, p.583-590, 1978.

PINSKY, M.L.; PALUMBI, S.R. Meta-analysis reveals lower genetic diversity in overfished populations. Mol. Ecol., v.23, p.29-39, 2014.

POVH, J.A.; LOPERA BARRERO, N.M.; RIBEIRO, R.P. et al. Monitoreo genético de programas de repoblamiento de peces mediante marcadores moleculares. Cienc. Invest. Agrar., v.35, p.25-35, 2008.

RIBEIRO, R.P.; LOPERA-BARRERO, N.M.; SANTOS, S.C.A. et al. Genetic diversity of pacu for restocking programs in the Tietê and Grande rivers, Brazil. Semin. Cienc. Agrar., v.35, p.3807-3826, 2015.

RIBOLLI, J.; MELO, C.M.R.; ZANIBONYFILHO, E. Genetic characterization of the Neotropical catfish Pimelodus maculatus (Pimelodidae, Siluriformes) in the upper Uruguay river. Genet. Mol. Biol., v.35, p.761769, 2012.

ROUSSET, F. Genepop 2007: a complete reimplementation of the GENEPOP software for Windows and Linux. Mol. Ecol. Res., v.8, p.103106, 2008.

TAMURA, K.; PETERSON, D.; PETERSON, N. Molecular evolutionary genetics analysis using maximum likelihood, evolutionary distance, and maximum parsimony methods. Mol. Biol. Evol., v.28, p.2731-2739, 2011.

VAN OOSTERHOUT, C.; HUTCHINSON, W.F.D.; WILLS, P.M.; SHIPLEY, P. Microchecker: software for identifying and correcting genotyping errors in microsatellite data. Mol. Ecol. Notes, v.4, p.535-538, 2004.

WRIGHT, S. Evolution and genetics of population. Chicago: University of Chicago Press, 1978. 580p.

YAZBECK, G.A.; KALAPOTHAKIS, E. Isolation and characterization of microsatellite DNA in the piracema fish Prochilodus lineatus (Characiformes). Genet. Mol. Res., v.6, p.10261034, 2007.

YEH, F.C.; BOYLE, T.Y.Z.; XIYAN, J.M. PopGene version 131: Microsoft Window-based freeware for population genetic analysis. Canada: University of Alberta and Center for International Forestry Research, 1999. 29p. 